\title{
Contraptions and STEM education: a Brazilian case study
}

\author{
Pedro Z. Caldeira ", Ana Paula Bossler \\ Universidade Federal do Triângulo Mineiro
}

How to cite this paper: Caldeira, P. Z., Bossler, A. P. (2019). Contraptions and STEM education: a Brazilian case study. The Educational Review, USA, 3(12), 235-240.

http://dx.doi.org/10.26855/er.2019.12.005

*Corresponding author: Pedro Z. Caldeira, Universidade Federal do Triângulo Mineiro.

\begin{abstract}
In a Media \& Education course of Mathematics and Natural Sciences graduations two teams of four students had to develop from scratch a contraptionwith at least 10 steps that embodied different types of knowledge from at least two natural sciences (for instance, Chemistry and Physics) in several steps and included one scientific experiment. Students also needed to explain to their colleagues of the other team the content knowledge embodied in their machine and the experimental results they obtained with the machine. One team developed a 10-step contraption that included knowledge from Chemistry and Physics and that ended with a Chemical experiment (a glass fell on a candle in the middle of a dish full of water; when the candle was extinguished the oxygen was substituted by water). At first the students of this team could not fully explain the experimental result: they mentioned air pressure differences but did not explain why pressure is involved.The other team developed a 11-step contraption that included only knowledge from Physics, and as its ninth step showed a Physics experiment (the energy needed to overcome the resistance of gravity). The students failed to recognize the experiment.Using the variation theory of learning principles, the professor asked students for scientific full explanations that three days after they needed to give to their classmates. The experiment explanationswere given very satisfactorily.
\end{abstract}

\section{Keywords}

contraption, variation theory of learning, instructional responsibility, discourse responsibility

\section{Introduction}

Designing an engaged learning setting with the help of technology is a rather easy task, especially if several engaged learning indicators are present such as learners' involvement in a collaborative, authentic and challenging task, learners responsibility over their learning, or teachers / lecturers acting as facilitators, guides or co-learners / co-investigators (Jones, Valdez, Nowakowski,\&Rasmussen, 1995; Hung, Tan, \& Koh, 2005; Oliver, 2008).

However, if these engaged learning indicators are fully applied, one possible consequence is the development of depedagogized school settings, with strong negative impacts on school achievement (Marton, 2015; Marton, \& Pang, 2006). That's why several researchers feel the need to better understand the role teachers and teaching play in student learning and achievement.

\section{Theoretical framework}

Students, in general, shouldn't have the full responsibility for their school learning and achievement, and teachers should not have a mere facilitator or guide role in school settings (Hansson, 2010; Marton, 2015).

Therefore, on one hand, students can have a strong responsibility for their learning (for instance, with the help of engaging learning settings - Jones et al., 1995), on the other hand, teachers should exert their instructional responsibility 
(Hansson, 2010) to enhance their students' learning. For instance, classes where teachers exhibit more time in teacherlead learning tasks, students achieve higher learning results on mathematics (Hansson, 2010). Moreover, and per the variation theory of learning (Marton, 2015; Marton, \& Pang, 2006), students can attain higher achievement if: i. their instructional environment is designed to present them "various patterns of sameness and difference" (Gu, 2011, as cited in Marton, 2015, p. 247) regarding the object of learning (Marton, 2015) and, counterintuitively, ii. students must learn simultaneously two or more things instead of one at a time (Kullberg et al., 2016).

The variation on objects of learning and inducing students to learn two or more things simultaneously are carried out through teachers' classroom discourse, namely the questions the teacher asks students and the tasks the teacher demand students to complete (Marton, 2015; Marton, \&Tsui, 2004). For instance, asking students questions that requires a Yes or No answer or that require a single recognition of a phenomenon elicits more superficial learning than asking students a Why question or to explain a scientific event, as they need to understand the underlying scientific concepts and knowledge, that elicits a deeper learning (Marton, 2015).

\section{Methodology}

In a Media \& Education course of the second year of two Rural Education teachers initial training graduations (Natural Sciences -Biology, Chemistry and Physics- and Mathematics), lecturers aimed to work with students on two major topics: media as information production with instruction purposes and media as information consumption for learning purposes. But the lecturers' final objective was that students should think media critically and to understand and use media as part of the instruction and understand the impact of the teachers' classroom discourse on students' learning and achievement.

The course had a total of 45 hours of classroom work and, in a process of co-teaching, two lecturers were always simultaneously present in the classroom. To fulfill the course learning objectives, the lecturers asked students to design and assemble a contraption in small collaborative groups.

A contraption is a sequence of interconnected actions to accomplish a usually simple task in a rather complicated manner (for instance, raise a flag, light a bulb or blow a balloon). Figure 1 represents a contraption: the machine starts when a marble is released (A) and finishes when a light bulb is lightened (B).

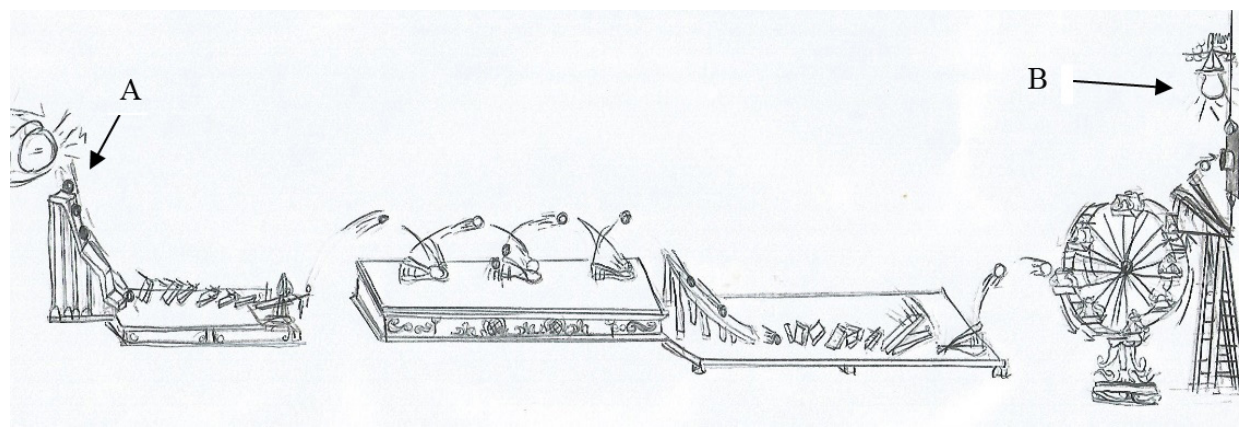

Figure 1. A typical contraption(author: Alexandre Caldeira)

The student groups had to comply with the following instructions: the designed should be entirely decided by the student groups, the machine should be completely functional, the students had the full responsibility of the machines' assembling, the machine should include at least a science experiment, and the machines must show a sequence of at least 10 interconnected actions. The running of the machines was filmed for further classroom discussion and analysis.

Finally, but not explicit from the beginning, lecturers also wanted to understand how students verbally analyzed and explain the functioning of their machines. Thus, the lecturers as the exercise final step decided to: i. force the students to do more than one learning simultaneously (Kullberg et al., 2016) and, ii.pedagogized the exercise asking students to explain the scientific principles underlying their machine run.

\section{Study 1 - Designing, assembling and discussing a contraption}

Although the student groups designed and assembled 12 contraptions, only twoof them are analyzed in this paper as it was the only ones that were completed before the last class.

The first group had two students of the Natural Sciences graduation and two students of the Mathematics graduation and 
the second group had four students of the Natural Sciences graduation.

The students' original ideas and designs were completed in one weekend and both groups needed two more days to finish assembling the contraption. The running of the machineswas filmed less than one week after the exercise was delivered.

Contraption's functioning description (follow the arrows - see Figure 2 - the first group machine ${ }^{1}$ - the contraption, aiming to ease the teachers' bureaucracy (a stamping machine), starts at A, where a rolling marble is released that descends on several slightly inclined planes to point B. Here the marble takes down the first piece of domino, which in a cascade effect loosens a lever in $\mathrm{C}$. The lever again releases another marble in $\mathrm{D}$, which descends through another inclined plane, triggering at the end (E) another lever that throws a third marble upwards, activating a third lever in F. This lever releases a string attached to a falling weight that stamps a paper in $\mathrm{G}$ (this machine goal).

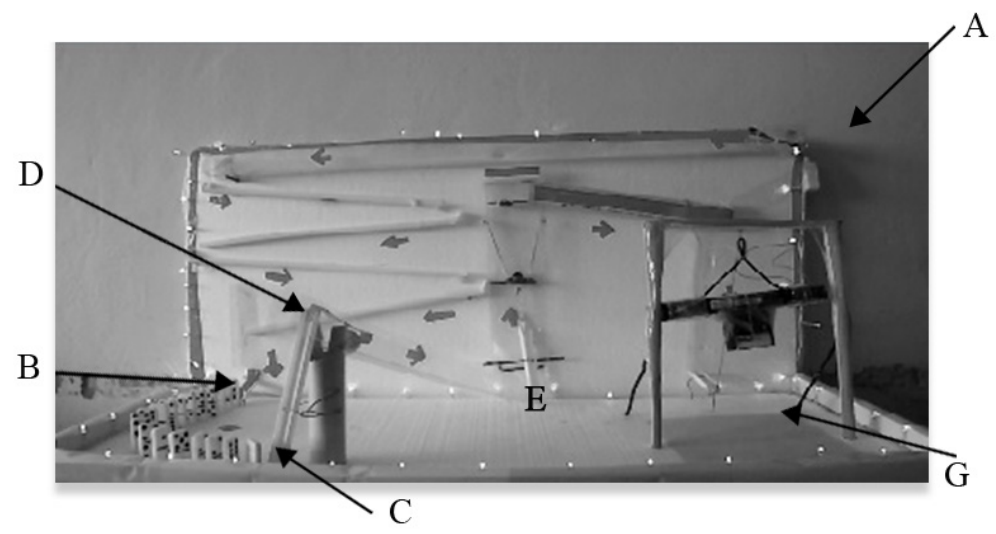

Figure 2. The firstcontraption (a stamping machine)

Contraption's functioning description (see Figure 3 - second group machine ${ }^{2}$ ) - this machine was assembled to extinguish a candle. Amini truck with a burning candle was released. The candle burns a string that releases another mini truck placed at the top of an inclined plane. The second mini truckruns into a lever disengaging a marble that descends inside of an inclined tube. At the end of the tube,the marble collides with a pen that releases another marble in an inclined plane. This marble starts a domino chain reaction that ends when a glass falls over a burning candle placed in the middle of a plate filled with water. When the candle flame consumes all the oxygen, the water starts to fill the glass (a very common Chemical experiment - the goal of this machine).

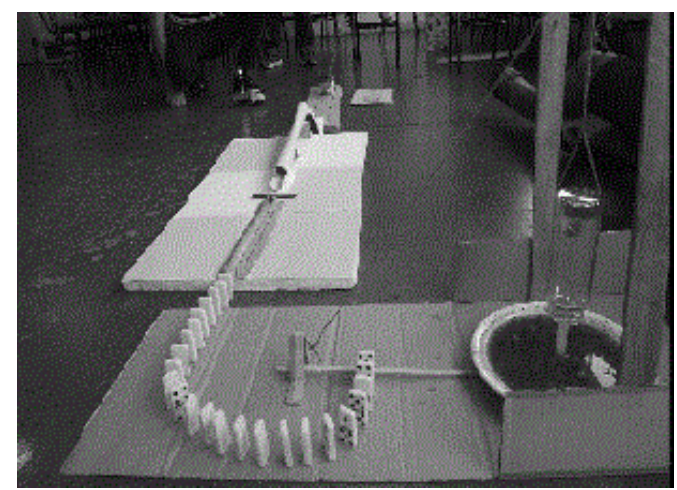

Figure 3. The second contraption

Right after filming the machine running, one lecturer debriefed the exercise with the groups, one at a time, asking students to indicate the scientific and mathematical knowledge included in the different machine components.

\footnotetext{
${ }^{1}$ Online at https://www.youtube.com/watch?v=JYZ4F8_wSAo (Brazilian extended version) and https://www.youtube.com/watch?v= SJ05zw857W8\&feature=youtu.be (English-speaking short version)

${ }^{2}$ Online at https://www.youtube.com/watch? $\mathrm{v}=\mathrm{x} 9 \mathrm{jyY} Y \mathrm{VU} 18 \mathrm{~s} \& \mathrm{t}=5 \mathrm{~s}$.
} 


\section{Study 1 - Results}

The students of the first group failed to explain the machines' design and functioning using scientific concepts and terms, except the one related to gravity (gravity tout court, without even linking the words gravity and force). They apply the common-sense language and the one they remembered from the high school to explain the scientific knowledge included in some machine components: action-reaction, fall out, chain effect or thrust. The students recognized less than half of the Physics phenomena and none of the Mathematical principles included in their contraption. For instance, they failed to recognize concepts like: stability, equilibrium point, forces, gravitational force, gravitational field, balancing forces, impulse, potential energy, kinetic energy, friction, energy needed to overcome the resistance of gravity, geometry, inclined plane force components, segmentslope, chain reaction / cascade effect, or causality.

The students of the second group also failed to explain the machines' design and functioning using scientific concepts and terms, but they recognized the experiment included in the machine run. They tried to explain the experiment but using only pressure to describe why the water started to fill the glass.

\section{Study 2 - Explaining the contraption to the lecturer and to the classmates}

The same lecturer, one week later had semi-structured interviews with the two groups, challenging the students to present to their classmates all the scientific principles included in the machine's running, thus introducing a variation on the object of learning: The lecturer stressed the need that students should identify the scientific and mathematical phenomena and principles underlying the machine run, with the special care to apply the appropriate scientific and mathematical terms, thus promoting the learning of two things simultaneously.

With this approach, lecturer shifts the object of learning from the mere recognition of scientific phenomena and mathematical principles to the explanation of these same scientific phenomena and mathematical principles, compelling students to apply a more appropriate vocabulary and thus promoting a deeper learning of scientific and mathematical knowledge. Applying appropriately scientific phenomena and mathematical principles are considered to have a positive impact on learning (Moje, 1995), as students' "progress faster and further if they are appropriately equipped linguistically." (p. 7)

\section{Study 2 - Results}

The students planned independently the presentation to their classmates. Their main goals were to stress the scientific and mathematical knowledge included in the machine run and to apply the appropriate vocabulary to explain the different machine's components.

The second group didn't finish the task, but the students explained more correctly to the lecturer the scientific phenomena included in the experiment: the pressure difference inside and outside the cup causes water to fill the volume previously occupied by oxygen prior to burning completely.

Physical phenomena underlined in the students' presentation (first group) -the students indicated almost $90 \%$ of the Physics phenomena and general principles included in the machine running, but they usually failed to present the details of these principles. For instance, they explained the gravitational force as the driving force that puts the marble in motion, but they don't consider the friction as the explaining principle of the marble complete stop in several filmed trials. Students identified most of the Physics phenomena included in the machine run, namely: stability, equilibrium point, forces, gravitational force, balancing forces or impulse. But they failed to comment on gravitational field, potential energy, kinetic energy, friction, or causality. They failed to apply the appropriate scientific vocabulary on only two occasions: instead of applying the expressions 'chain reaction' or 'cascade effect' to the domino effect they used the expression 'chain effect' (a fitness term); they also failed to apply the expression 'force needed to overcome the resistance of gravity' when the marble is thrown upwards in C (see Figure 4).

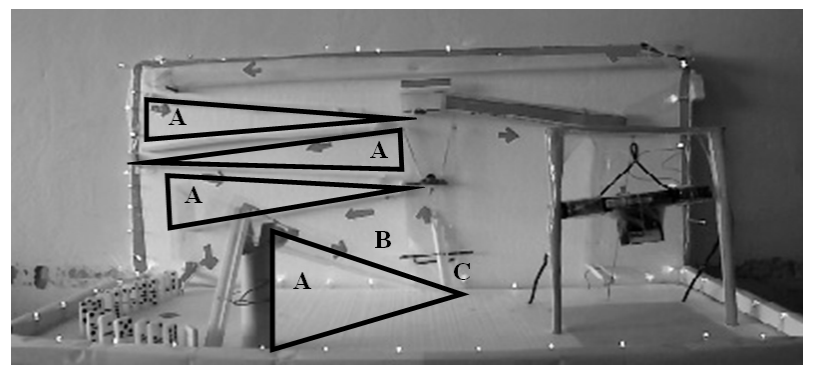

Figure 4. The students' scientific and mathematical explanations of their contraption's running 
Mathematical principles underlined in the students' explanation (first group) - students identified mainly two mathematical principles included in the machine run: geometry, namely geometric figures present in the machine structure (mainly triangles and rectangles - marked with an A), and the slope of a segment, represented by the hypotenuse (marked with a B - that they successfully related with inclined plane force components), needed to the marble gain speed to activate the lever that throws another marble upwards (marked with a C).

\section{Results}

The results of the two studies are presented in Table 1.

Table 1. Results of the Study 1 and Study 2.

\begin{tabular}{lcccccc}
\hline & \multicolumn{2}{c}{ Group 1 } & & \multicolumn{2}{c}{ Group 2 } \\
\cline { 2 - 3 } \cline { 5 - 6 } & Study 1 & Study 2 & & Study 1 & Study 2 \\
\hline Recognition of general Chemical phenomena & --- & --- & & 1 & 2 \\
Recognition of general Physics phenomena & 5 & 12 & & 2 & --- \\
Recognition of Mathematics principles & 0 & 2 & & -- & -- \\
Appropriate use of vocabulary & 1 & 25 & & 1 & 2 \\
\hline
\end{tabular}

These results reveal that: i. students identified more scientific phenomena and mathematical principles in study 2 and ii. they also acquired and applied more correctly and extensively the appropriate vocabulary in study 2 .

\section{Implications/Discussion}

Inducing students to approach differently the machine's running had a positive impact on their learning: The students of the first group jumped from a recognition of about $40 \%$ of the Physics phenomena and none of the Mathematics principles included in the machine's functioning on Study 1 to a recognition and explanation of about $90 \%$ of the Physics phenomena, and two Mathematics principles on Study 2. The students of the second group, even without completing the task (explaining the machine's running to their classmates), only recognized $25 \%$ of the Chemical phenomena in Study 1 and 50\% in Study 2, using the appropriate scientific terms.

Therefore, as Marton expected (2015; Marton, \& Pang, 2006), asking students to present and explain to their classmates the scientific phenomena and mathematical principles underlying the functioning of the machine induced a variation on the object of learning and allowed them to better understand how the machine works and to relate components of the machine's running with scientific and mathematical phenomena and knowledge.

And more, as experimental research already shown (Kullberg et al., 2016), encouraging students to learn two things simultaneously have a positive impact on student learning: Understanding the scientific and mathematical knowledge underlying the machine's functioning and explaining it to their classmates applying appropriate vocabulary promoted students' learning.

The final class discussion about the use of contraptions with instructional and learning objectives emphasized that designing, assembling and analyzing contraptions may contribute simultaneously to more engaging learning settings and to improve student learning.

\section{Conclusions}

The design, assembly and analysis of a contraption in small collaborative groups is a powerful way to promote simultaneously an engaged learning setting, a variation on the object of learning and inducing the learning of two or more things at once, thus improving student learning and achievement, provided there is an adequate pedagogized environment where the teacher leads the students' learning (teachers' instructional responsibility - Hansson, 2010). Shifting the object of learning from simple recognition of scientific phenomena and mathematical principles to the explanation to the classmates of these phenomena and principles has a very positive impact on student learning: They go from simple recognition to the understanding of the Physicaland Chemicalphenomena and the Mathematics principles 
previously identified.

Therefore, besides an instructional responsibility to promote a teaching-lead learning environment, improving student learning, teachers also have a discourse responsibility to provide pedagogized school settings supporting one or more variations on the object of learning (Marton, 2015; Marton, \& Pang, 2006) and encouraging the learning of several things at once (Kullberg et al., 2016;) thus promoting the student learning and achievement.

\section{Acknowledgement}

The research underlying this paper was funded by Fapemig (Minas Gerais state agency for research support and funding - CHE - APQ-01590-13).

\section{References}

Jones, B.F., Valdez, G., Nowakowski, J.,\&Rasmussen, C. (1995). Plugging in: Choosing and Using Educational Technology. Washington DC: Council for Educational Development and Research.

Hansson, Å. (2010). Instructional responsibility in mathematics education: Modelling classroom teaching using Swedish data. Educational Studies in Mathematics, 75, 171-189.

Herrington, J., Oliver, R., \&Reeves, T. (2003). Patterns of engagement in authentic learningenvironments. Australian Journal of Educational Technology, 19, 59-71.

Hung, D., Tan, S. C., \&Koh, T. S. (2005). Engaged Learning: Making Learning an Authentic Experience. In D. Hung \& M. S. Khine (Eds.), Engaged Learning with Emerging Technologies. Dordrecht: Springer.

Kullberg, A., Runesson, U., Marton, F., Vikström, A., Nilsson, P., Märtensson, P., \&Häggström, J. (2016). Teaching one thing at a time or several things together? - teachers changing their way of handling the object of learning by being engaged in a theory-based professional learning community in mathematics and science. Teachers and Teaching: Theory and Practice, 22, 745-759.

Marton, F. (2015). Necessary conditions of learning. New York, NY: Routledge.

Marton, F., \&Pang, M. F. (2006). On Some Necessary Conditions of Learning. Journal of the Learning Sciences, 15, 193-220.

Marton, F., \&Tsui, A. B. M. (2004). Classroom Discourse and the Space of Learning, Mahwah, NJ: Lawrence Erlbaum Associates.

Moje, E. B. (1995) Talking about science: an interpretation of the effects of teacher talk in a high school science classroom. Journal of Research in Science Teaching, 32, 349-371.

Oliver, R. (2008). Engaging first year students using a Web-supported inquiry-based learning setting High Education, $55,285-301$. 